\title{
Geochemical Response to Oceanic Anoxic Event 1a in Lower Aptian Pelagic Sediments of the Subbetic Basin, Spain
}

\author{
CARLOS HERDOCIA AND FLORENTIN J M \\ MAURRASSE
}

Florida International University

Presenting Author: cherd002@fiu.edu

Oceanic Anoxic Event 1a (OAE 1a) is usually associated with organic-rich black shales coeval with increased volcanic activity coupled with eustatic sea level rise, a sluggish oceanic circulation, increased continental runoff, and elevated primary productivity. The event has been identified within the Aptian of the La Frontera section, in the Subbetic Basin of Southern Spain. This study focuses on $\sim 28 \mathrm{~m}$ at La Frontera and provides new data on total inorganic carbon (TIC), total organic carbon (TOC), major elements (Al, Si, \& Ti), biolimiting elements (Fe \& P), redox sensitive trace elements (RSTEs; $\mathrm{V}, \mathrm{Cr}, \mathrm{Ni}, \mathrm{Cu}, \mathrm{Mo}, \& \mathrm{U}$ ) and clay content. The succession includes three units based on the lithology. Unit I, the lowermost $13.16 \mathrm{~m}$, consists of interbedded limestone ( $>65 \%$ TIC), marly limestone $(60-65 \%$ TIC), and marlstone (30-60\% TIC). Unit II that characterizes OAE 1a is $4.83 \mathrm{~m}$ thick $(13.42 \mathrm{~m}-18.25 \mathrm{~m})$ and comprises essentially siliceous shales $(<10 \%$ TIC), including an intercalated calcareous shale (10-30\% TIC) layer. Unit III, the uppermost $9.16 \mathrm{~m}(18.77 \mathrm{~m}-27.93 \mathrm{~m})$ of the section, contains calcareous shales and marlstones with one limestone layer. TOC in Unit I remains below $1.00 \%$, averages $0.25 \%$; highest values occur in Unit II with a maximum of $3.39 \%$, then decrease to an average of $0.24 \%$ in Unit III. Major element values increase where TIC is low and become particularly enriched within Unit II. Biolimiting elements $(\mathrm{P}, \mathrm{Fe})$ share no correlation with TOC $(\mathrm{r}=-0.10$ and 0.15 , respectively) implying that enhanced productivity was not a major factor in the preservation of organic matter. Clay content varies, most notably smectite abundance increases from an average of $23.5 \%$ (Unit I) to an average of $44.67 \%$ (Unit II) and then decreases to $24.8 \%$ (Unit III). RSTE's (V, Cr, Cu, Mo, \& U) correlate positively with $\mathrm{TOC}$ and $\mathrm{Al}$, with highest values within Unit II. These results indicate that this part of the basin did not experience strong reducing conditions during OAE1a and preservation of $\mathrm{OM}$ is likely related to terrestrial fluxes with a possible volcanic influence as indicated by the temporal variation in the clays. 